\title{
Oral Versus Vaginal Progesterone in Preterm Labor
}

\author{
Controlled \\ Mostafa AH. Abd Elaziz \\ Study \\ Department of Obstetrics and Gynecology, Faculty of Medicine, Suez Canal University, \\ Egypt
}

\begin{abstract}
Background: Preterm labor (PTL) remains a distressing issue in modern obstetrics, and still associated with poor impact on the perinatal outcomes world-wide. Progesterone plays a vital role in preventing the PTL.

Objective: To compare different route of progesterone administration on the perinatal outcomes.

Patients and Methods: It was a prospective comparative clinical trial, conducted at Suez Canal University Hospitals, Ismailia from December 2015 to January 2017. One hundred and thirty eight pregnant patients were selected at 20-24 weeks gestation' at risk of PTL and were classified into: 72 women received oral dydrogesterone $10 \mathrm{mg}$ twice a day [Duphastone ${ }^{\circledR}$ ] (Oral group) and 66 women received vaginal progesterone $200 \mathrm{mg}$ vaginally twice a day [Prontogest $\left.{ }^{\circledR}\right]$ (vaginal group). The primary outcome measures were gestational age at delivery in weeks, birth weight in grams, Apgar score at 1 and 5 minutes, the need for neonatal intensive care unit admission and neonatal mortality.

Results: There was a significant difference between both group in favor to the vaginal group in all the studied outcome measures $(p$ value $<0.05)$ with the exception of the Apgar score at 5 minutes post delivery $(p$ value $=0.1)$. No cases of perinatal mortality in the vaginal group and only 3 cases in the oral group.

Conclusion: The vaginal route is of better and significant results.
\end{abstract}

Key Words: Adipokines, eclampsia, preeclampsia, ZAG Oral progesterone, preterm birth, preterm labor, vaginal progesterone

Received: 11 July 2017, Accepted: 22 July 2017

Corresponding Author: Dr Mustafa Abdelaziz, Department of Obstetrics \& Gynecology, Faculty of Medicine, Suez Canal University, Egypt, Tel.: 01006896445,,E-mail: drmustafa_ahmed@yahoo.com

ISSN: 2090-7625, November 2017, Vol.7, No. 4

\section{INTRODUCTION}

Preterm labor (PTL), delivery before completed 37 weeks gestations' is considered one of commonest causes of early newborn morbidity and even mortality and is associated with remote sequlae later in life, developmental and neurological disabilities ${ }^{[1-4]}$. The perinatal mortality is significantly higher in preterm than in term neonates, 40 times more ${ }^{[5,6]}$, and such mortality is reversely related to the gestational age (GA) at delivery but also still persists up to 36 weeks gestations ${ }^{[7]}$.

The incidence of the preterm neonatal morbidity and mortality is related to what we call prematurity complex syndrome (PCS) including respiratory distress syndrome which is the most frequent leading factor of early neonatal mortality. Other documented complications associated with the (PCS) are electrolyte imbalance; neurological complications (intraventricular hemorrhage and periventricular leukomalacia, with implications for ongoing cerebral dysfunction), high liability to infection, retinopathy of prematurity and necrotizing enterocolitis ${ }^{[8]}$

Being PTL still has high incidence, around $15 \%$ of all pregnancies, its prevention should be considered an essential issue in modern obstetrics ${ }^{[9,10]}$. Progesterone plays a vital role in pregnancy continuation by inhibiting the calcium-calmodulin-myosin light chain kinase system $^{[10]}$, establishing uterine quiescence. Also it has documented anti-inflammatory properties, alarming the known link between inflammatory processes, alterations in progesterone receptor expression and the onset of $\mathrm{PTL}^{[11]}$.

Progesterone is clinically applied and approved for the prevention of PTL. It can be used orally, vaginally or by injection. Natural progesterone and hydroxyl progesterone are the two accepted for usage during pregnancy ${ }^{[3]}$. There is still significant hesitation about the optimal progesterone type, route of administration, dosage and timing of start of therapy to prevent PTL in risky women ${ }^{[12]}$.

The objective of this study was the comparison of the effectiveness of oral to vaginal progesterone in cases of preterm labor regarding the perinatal outcome.

\section{PATIENTS AND METHODS}

After the agreement of the Ethics Committee of the Faculty of Medicine, Suez Canal University 
this comparative clinical study was conducted at the Obstetrics and Gynecology Department of the Suez Canal University Hospitals, Ismailia from December 2015 to January 2017. All participants gave oral and written informed consent before to be recruited into the study.

Being suggested by some studies that the use of progesterone in pregnant women at high risk for (PTL) is associated with a drop of in preterm delivery rate by about $60 \%$ to $78 \%{ }^{[13]}$; a more practical evaluation of the influence of progesterone may be a decrease of $50 \%$ in the prematurity rate. A power calculation at the start of the study indicated that at least 48 pregnant women would have to be integrated in each group to obtain a study power of $90 \%$ at a significance level of .05 (two tailed $)^{[14]}$

One hundred and sixty pregnant women were selected from patients' high risk for PTL. They were divided equally into two groups (80 patients for each group). One group received vaginal progesterone 200 mg vaginally twice a day (Prontogest $\AA$ ) and the other group received oral dydrogesterone $10 \mathrm{mg}$ twice a day (Duphastone ${ }^{\circledR}$ ).

Our inclusion criteria were: (a) singleton pregnancy, (b) living fetus with gestational age (GA) 20-24 weeks gestation' (calculated by regular period and documented with early ultrasound examination) and (c) presence of risk factor for PTL as: history of previous spontaneous PTL in the past singleton pregnancy, history of previous spontaneous premature rupture of membranes in the past singleton pregnancy, short cervix $(<3 \mathrm{~cm})$ documented during midtrimesteric transvaginal sonographic (TVS) examination. Exclusion criteria were: (a) medical or obstetric conditions requiring termination of pregnancy, (b) contraindication to progesterone administration or its use earlier in this pregnancy, (c) congenital fetal anomalies, (d) cervical cerclage, (e) intrauterine fetal death, (f) low lying placenta and (g) coagulation disorders.

All included patients were submitted to a complete medical history including name, age, job, educational level, smoking status, parity, and mode of the delivery. Age was categorized into 3 groups: less than 18 years, 18-35 years and more than 35 years. Job was classified into house wife, employee and advanced employee. Educational level was categorized as uneducated, educated and highly educated. Smoking status was classified as non smoker or smoker. By parity, women were classified as nullipara, multipara, grand multipara (more than para 5). Mode of delivery was either by vaginal delivery (VD) or by cesarean section (CS). BMI was grouped into 4 categories: under weight ( $<19 \mathrm{~kg} / \mathrm{m} 2)$, average weight $(19-24.9 \mathrm{~kg} / \mathrm{m} 2)$, over weight (25.0-29.9 kg/m2), obese (30.0-39.9 kg/m2) and morbidly obese $(\geq 40 \mathrm{~kg} / \mathrm{m} 2)$.

All cases were followed up in the antenatal care clinic of our hospital every two weeks (high risk) till delivery. Cases that developed uterine contractions or continuous abdominal pains were coming as soon as possible and examined clinically and sonographically to diagnose the onset of PTL and classify its degree (advanced, early, threatened or just false labor pains). Compete urinanalysis could be done or repeated at such stage and indicated treatment given accordingly, including, tocolytic therapy (calcium channel blockers), antibiotics according to compete urinanalysis and culture. Betamethasone treatment, $12 \mathrm{mg}$ intramuscular injection two doses 24 hours apart) to enhance fetal lung maturity was administrated whenever possible and progesterone was continued in all cases till delivery or 36 ' weeks gestation.

Our perinatal outcome measures were; GA at delivery in weeks, birth weight (B.WT) in grams, Apgar score at 1 and 5 minutes, the need for neonatal intensive care unit (NICU) admission and neonatal mortality

\section{Statistical analysis}

Data were statistically described in terms of mean and standard deviation, frequencies (number of cases) and percentages when appropriate. Comparison between both groups was done using Chi-Square test in the cross tabulation of the socio-demographic data between both groups and independent sample (t) test to compare numerical variables between both. $P$ values less than 0.05 were considered statistically significant. All statistical calculations were done using computer program SPSS (Statistical Package for the Social Science; SPSS Inc., Chicago, IL, USA) release 22 for Microsoft Windows.

\section{RESULTS}

One hundred and sixty patients were selected from those women high risk for the development of PTL. They were divided equally into two groups according to the type and route of administration of progesterone given as a prophylactic to the development of PTL. Eighty patients were given oral progesterone, Dydrogesterone, $10 \mathrm{mg}$ twice a day, Duphastone ${ }^{\circledR}$ (oral group) and the other 80 patients given vaginal progesterone $200 \mathrm{mg}$ twice a day, Prontogest $\AA$ (vaginal group). Twenty two women were dropped out, 8 from oral group and 14 from the vaginal group (didn't follow antenatal care program, refused admission when indicated or delivered outside our hospitals). So the net population in the study is 138 women; 72 women for the oral group and 66 women for the vaginal group. 
Table 1: Demography

\begin{tabular}{|c|c|c|c|c|c|c|}
\hline & & \multicolumn{2}{|c|}{ Oral group } & \multicolumn{2}{|c|}{ Vaginal group } & \multirow[b]{2}{*}{$P$. value* } \\
\hline & & NO. & $\%$ & NO. & $\%$ & \\
\hline \multirow{4}{*}{$\begin{array}{c}\text { Age } \\
\text { group (years) }\end{array}$} & $<18$ & 3 & 4.2 & 5 & 7.6 & \multirow{3}{*}{0.414} \\
\hline & $18-35$ & 54 & 75 & 43 & 65.2 & \\
\hline & $>35$ & 15 & 20.8 & 18 & 27.3 & \\
\hline & Mean \pm SD & \multicolumn{2}{|c|}{$28.7 \pm 7.2$} & \multicolumn{2}{|c|}{$28.1 \pm 8$} & $0.659 \bullet$ \\
\hline \multirow{3}{*}{ Job } & House wife & 24 & 33.3 & 24 & 36.4 & \multirow{3}{*}{0.18} \\
\hline & Embolyee & 39 & 54.2 & 27 & 40.9 & \\
\hline & $\begin{array}{l}\text { Advanced } \\
\text { Embolyee }\end{array}$ & 9 & 12.5 & 15 & 22.7 & \\
\hline \multirow{3}{*}{ Education } & Uneducated & 13 & 18.1 & 6 & 9.1 & \multirow{3}{*}{0.227} \\
\hline & Educated & 53 & 73.63 & 51 & 77.3 & \\
\hline & Highly educated & 6 & 8.3 & 9 & 13.6 & \\
\hline \multirow{2}{*}{ Smoking } & Non-smoker & 60 & 83.3 & 54 & 81.8 & \multirow{2}{*}{0.495} \\
\hline & Smoker & 12 & 16.7 & 12 & 18.2 & \\
\hline \multirow{3}{*}{ Parity } & PG & 12 & 16.7 & 12 & 18.2 & \multirow{3}{*}{0.083} \\
\hline & MG & 39 & 54.2 & 45 & 68.2 & \\
\hline & GMP & 21 & 29.2 & 9 & 13.6 & \\
\hline \multirow{2}{*}{ Mode } & VD & 48 & 80 & 33 & 61.1 & \multirow{2}{*}{0.083} \\
\hline & CS & 12 & 20 & 21 & 38.9 & \\
\hline \multirow{5}{*}{ BMI } & Underweight & 3 & 4.2 & 6 & 9.1 & \multirow{5}{*}{0.555} \\
\hline & average & 33 & 45.8 & 30 & 45.5 & \\
\hline & & & & & & \\
\hline & Overweight & 18 & 25 & 18 & 27.3 & \\
\hline & Obese & 18 & 25 & 12 & 18.2 & \\
\hline
\end{tabular}

*=Chi square, $\bullet=$ independent sample $(\mathrm{t})$ test, $\mathrm{PG}=$ primigravida, $\mathrm{MG}=$ multigravida, $\mathrm{GMP}=$ grand multipara, $\mathrm{VD}=$ vaginal delivery, $\mathrm{CS}=$ cesarean section, $\mathrm{BMI}=$ body mass index.

The mean age for all the whole studied population was $(28.4 \pm 7.6)$ years ranged from 17 to 42 years old. Table (1) showed the distribution of the demographic data among the both groups. Of note that the mean age for oral group was (28.7 \pm 7.2$)$ and for the vaginal group was (28.1 \pm 8) which showed insignificant difference statistically ( $p$ value 0.659). Most of our patients were within the age group (18-35) years old ( $75 \& 65.2 \%)$, educated (73.63\& $77.3 \%$ ), Employee (54.2 \& 40.9\%), non smoker $(85.7 \% \&$ $82.6 \%)$, MP (54.2\% \& 68.2\%), delivered vaginally ( $80 \% \&$ $61.1 \%)$ and had average weight (45.8\& $45.5 \%)$ for the oral and the vaginal group respectively. Of note all the sociodemographic data showed no significant difference between both groups ( $p$ value $>0.05$ ). 
Table 2: Risk factors, presentation and management.

\begin{tabular}{|c|c|c|c|c|c|c|}
\hline & & \multicolumn{2}{|c|}{ Oral group } & \multicolumn{2}{|c|}{ Vaginal group } & \multirow{2}{*}{$P$. value* } \\
\hline & & NO. & $\%$ & NO. & $\%$ & \\
\hline \multirow{7}{*}{ Risk factors } & B.V & 9 & 12.5 & 12 & 18.2 & \multirow{7}{*}{0.587} \\
\hline & H.PROM & 15 & 20.8 & 12 & 18.2 & \\
\hline & H.PTL & 12 & 16.7 & 18 & 27.3 & \\
\hline & C.U.M.F & 3 & 4.2 & 3 & 4.5 & \\
\hline & Short Cervix & 9 & 12.5 & 6 & 9.1 & \\
\hline & Threatened Miscarriage & 12 & 16.7 & 9 & 13.6 & \\
\hline & UTI & 12 & 16.7 & 6 & 9.1 & \\
\hline \multirow{5}{*}{$\begin{array}{c}\text { Time of } \\
\text { Presentation }\end{array}$} & 20 weeks & 18 & 25 & 9 & 13.6 & \multirow{5}{*}{0.152} \\
\hline & 21 weeks & 12 & 16.7 & 21 & 31.8 & \\
\hline & 22 weeks & 15 & 20.8 & 15 & 22.7 & \\
\hline & 23 weeks & 15 & 20.8 & 9 & 13.6 & \\
\hline & 24 weeks & 12 & 16.7 & 12 & 18.2 & \\
\hline \multirow{3}{*}{ Admission } & $\mathrm{NON}$ & 48 & 66.7 & 45 & 68.2 & \multirow{3}{*}{0.211} \\
\hline & ONCE & 15 & 20.8 & 18 & 27.3 & \\
\hline & TWICE & 9 & 12.5 & 3 & 4.5 & \\
\hline \multirow{3}{*}{ Treatment } & ANTIBIOTICS & 21 & 29.2 & 15 & 22.7 & \multirow{3}{*}{0.691} \\
\hline & TOCOLYTICS & 27 & 37.5 & 27 & 40.9 & \\
\hline & $\begin{array}{c}\text { BETAMETHASONE } \pm \\
\text { ANTIBIOTICS } \pm \\
\text { TOCOLYTICS }\end{array}$ & 24 & 33.3 & 24 & 36.4 & \\
\hline
\end{tabular}

*=Chi square, B.V= bacterial vaginosis, H.PROM= history of premature rupture of membranes, H.PTL= history of preterm labor, $\mathrm{CUMF}=$ congenital uterine malformation, $\mathrm{UTI}=$ urinary tract infection.

Table (2) showed the distribution of the risk factors, time of presentation, admission and management offered among the both groups. Of note most of the oral group presented with history of premature rupture of membranes in the previous pregnancy $(20.8 \%)$ followed by history of preterm labor in the previous pregnancy $(16.7 \%)$ while most of the patients in the vaginal group presented with history of preterm labor in the previous pregnancy $(27.3 \%)$ followed by history of premature rupture of membranes in the previous pregnancy and bacterial vaginosis $(18.2 \%)$ for each. It is noted as expected that the least presentation in both group was short cervix (12\% and $9.1 \%)$ for the oral and vaginal group respectively. Most of the oral group patients were presented within the 20 weeks' gestation (25\%) followed by 22 and 23 weeks' gestation (20.8\%) for each, while most of patients in the vaginal group presented within the 21 weeks' gestation (31.8\%) followed by 22 weeks' gestation $(22.7 \%)$.

Regarding the admission most of our population did not need admission (66.7\% and 68.2\%). The rest of them were admitted once $(20.8 \%$ and $27.3 \%)$ or twice $(12.5 \%$ and $4.5 \%$ ) in the oral and vaginal group respectively. The required treatment for our patients was just tocolytic 
agents to abort the attack of uterine contraction in $(37.5 \%$ and $40.9 \%$ ) or combined treatment (betamethasone \pm antibiotics \pm tocolytics $)$ in $(33.3 \%$ and $36.4 \%)$ and $(29.2 \%$ and $22.7 \%$ ) received just antibiotics, as mono therapy, in the oral and vaginal group respectively. All of those variables showed insignificant difference between the both studied groups ( $\mathrm{p}$ value $>0.05$ ).

Table 3: Comparison of outcome between the two studied groups.

\begin{tabular}{|c|c|c|c|c|c|c|}
\hline & & \multicolumn{2}{|c|}{ Oral group } & \multicolumn{2}{|c|}{ Vaginal group } & \multirow{2}{*}{$P$. value* } \\
\hline & & No. & $\%$ & NO. & $\%$ & \\
\hline \multirow{4}{*}{$\begin{array}{c}\text { GA at } \\
\text { termination } \\
\text { (weeks) }\end{array}$} & $<34$ weeks & 9 & 12.5 & 0 & 0 & \multirow{4}{*}{0.012} \\
\hline & $34-36$ 6/7weeks & 44 & 61.1 & 47 & 71.2 & \\
\hline & $>37$ weeks & 19 & 26.4 & 19 & 28.8 & \\
\hline & Mean \pm SD & & & & & \\
\hline \multirow{3}{*}{$\begin{array}{c}\text { BIRTH } \\
\text { WEIGHT } \\
\text { (Kg) }\end{array}$} & LOW (<2.5kg) & 12 & 25 & 0 & 0 & \multirow{3}{*}{$<0.001$} \\
\hline & Average & 60 & 83.3 & 66 & 100 & \\
\hline & Mean \pm SD & & & & & \\
\hline \multirow{2}{*}{$\begin{array}{l}\text { APGAR at } \\
\text { one minute }\end{array}$} & $<7$ & 19 & 26.4 & 6 & 9.1 & \multirow{2}{*}{0.007} \\
\hline & $>7$ & 53 & 73.6 & 60 & 90.9 & \\
\hline \multirow{2}{*}{$\begin{array}{l}\text { APGAR at } \\
\text { five minutes }\end{array}$} & $<7$ & 13 & 18.1 & 6 & 9.1 & \multirow{2}{*}{0.1} \\
\hline & $>7$ & 59 & 81.9 & 60 & 90.9 & \\
\hline \multirow{3}{*}{$\begin{array}{c}\text { NICU } \\
\text { admission }\end{array}$} & RDS & 6 & 40 & 4 & 66.7 & \multirow{3}{*}{0.045} \\
\hline & Sepsis & 3 & 20 & 0 & 0 & \\
\hline & TTNB & 6 & 40 & 2 & 33.3 & \\
\hline
\end{tabular}

*=Chi square, $\mathrm{GA}=$ gestational age, $\mathrm{NICU}=$ neonatal intensive care unit, $\mathrm{RDS}=$ respiratory distress syndrome, TTNB: transient tachypnea of new born.

Table (3) represented the distribution of the perinatal outcomes among the both groups. The mean GA of our population at the time of delivery was $36^{5 / 7} \pm 1^{2 / 7}$ weeks $\left(36^{4 / 7} \pm 1^{3 / 7}\right.$ weeks and $37 \pm 1^{0 / 7}$ weeks) for the oral and vaginal group respectively and it is considered significant difference ( $p$ value $=0.007$ ). Of note most of our patients delivered between $34^{0 / 7}$ and $36^{6 / 7}$ weeks' gestation, mild preterm $(61.1 \%$ and $71.2 \%)$ and a considered percentage delivered after the completed 37 weeks' gestation, full term, $(26.4 \%$ and $28.8 \%$ ) for the oral and vaginal group respectively. Regarding the severe prematurity, $<34$ weeks, only $(12.5 \%$ and zero \%) for the oral and vaginal group respectively, so that the maturity showed significant difference between the both groups ( $p$ value $=0.012$ ). The mean of birth weight in our population was $2.9 \pm 0.3 \mathrm{Kg}(2.87 \pm 0.378$ and $3 \pm 0.24 \mathrm{Kg}$ ) for the oral and vaginal group respectively, significantly different ( $p$ value $=0.022$ ). Of note most of our population delivered average-weight newborns $(83.3 \%$ and $100 \%$ ) for the oral and vaginal group respectively
( $p$ value $<0.001)$. The Apgar score at one minute post delivery was more than 7 in most of our population $(73.6 \%$ and $90.9 \%$ ) in the oral and vaginal group respectively and it is considered significant difference between both groups ( $p$ value $=0.007$ ). The Apgar score at five minutes post delivery was more than 7 in most of our population $(81.9 \%$ and $90.9 \%$ ) in the oral and vaginal group respectively and it is considered insignificant difference between both groups $(p$ value $=0.1)$.

Regarding the need for NICU admission there was significant difference between the both studied groups ( $p$ value $=0.045$ ). Although few number of our population was in need for NICU admission, RDS was the most frequent indication in the vaginal group $(66.37 \%)$ and was side by side with TTNB in the oral group (40\%). Three cases in the oral group ended with perinatal mortality, all of them were admitted to the NICU and died in the early neonatal period. 


\section{DISCUSSION}

In this clinical trial we compared the value of progesterone use (oral to vaginal route) as a prophylactic treatment in PTL and its effect on the perinatal outcomes. The net results of our work are; first, both routes of administration have a good implication on the perinatal wellbeing, and second, in comparison, the vaginal way has a significant and better impact on the prolongation of the GA and by the way on the birth weight. Regarding the development and the degree of the prematurity complex syndrome manifestations (RDS, Apgar score at one and five minutes post delivery and the need for NICU admission) the vaginal group showed a significant difference on all the studied variables except the Apgar score at 5 minutes post delivery.

The role of progesterone in pregnancy is unclear; however, the impact of progesterone on the myometrium is double action; it disturbs the estrogenic receptors at the myometrium and accordingly inhibits the estrogenic effect on the myometrium, oxytocin receptors sensitization in addition to its direct impact via its own receptors on the uterus $^{[14-16]}$. Thus, the contractile capacity is maintained under the influence of progesterone.

The exact mechanism by which progesterone prevents PTL is unknown, but there are two highly accepted mechanisms: (a) the anti-inflammatory effect that reverses the inflammatory process associated with PTL and, (b) the local increase in progesterone in gestational tissues counteracts the functional decrease in progesterone leading to PTL, in certain group of patients with PTL ${ }^{[17]}$.

In general, our study showed that the percentage of PTL was $72.5 \%$ for the whole population, $(73.6 \%$ and 71.2) for the oral and vaginal group respectively. Such significant difference may be related to that vaginal pessaries of progesterone are available and have the potential advantage of high uterine bioavailability ${ }^{[18]}$. In details, our study showed that vaginal application of progesterone was associated with significant prolongation of GA than when administrated orally, $(p$ value $=0.007)$ taking into consideration that most of our population in both groups delivered in the late preterm period $\left(34^{0 / 7}-\right.$ $36^{6 / 7}$ weeks' gestation), mild preterm, (61.1\% and $\left.71.2 \%\right)$ and a considered percentage delivered after the completed 37 weeks' gestation, full term, $(26.4 \%$ and $28.8 \%)$ for the oral and vaginal group, respectively.

Our result was supported recently by Neeta Natu et al, 2017, who reported that with vaginal progesterone the term delivery could approach (73.3\%), 11 out of 15 cases, while with oral progesterone the term delivery was just $(60 \%)$, 9 out of 15 cases $^{[19]}$. Their small sample size should be considered and evaluated.

Also SuLL et al, 2014, reviewed seven studies, involving 538 women, whose data suggested that the use of progesterone associated with a reduction of PTL and an increase in birth weight ${ }^{[20]}$.

In a review article, 2012, (which perused the 1983-2012 literature) Vincenzo et al. in the UK noticed that vaginal progesterone suppository (200 $\mathrm{mg}$ ) had a $44 \%, 37 \%$ and $43 \%$ drop of PTL. Moreover, in five studies reviewed the decline in PTL had been confirmed with vaginal progesterone suppository $(200 \mathrm{mg}$ ) and was statistically significant ${ }^{[21]}$.

Also Azza et al, 2012, confirmed that vaginal progesterone was nearly as equally effective as intra muscular progesterone in the prevention of PTL in women at risk ${ }^{[23]}$. Such results are strongly supported and approved our study, because if the vaginal route could approach the results of intramuscular route, in their work, its more logic and easily accepted to see significant better results of the vaginal route over the oral one in our research.

Da Fonseca et al, 2003, found that out of 72 patients given progesterone $21 \%$ has PTL; more women were delivered before 34 weeks in the placebo group $(18.5 \%)$ than in the progesterone group $(2.7 \%)(\mathrm{P}<.05)^{[23]}$.

In the opposite side Wilasinee et al, 2016, found that the rate of uterine contractions and the interval till delivery were indifferent between the dydrogesterone and placebo groups. Also the fetal maturity at delivery, perinatal outcomes, compliance and side effects were almost the same ${ }^{[24]}$. We could explain such conflict with our results by; first, the time of onset, duration and dose of the progesterone used, second, different sample size and third, different population and demographics and fourth the different risk factors they included in their work. In our study we included only the risky population and could fix almost all the demographic and risk factors variables among the both studied groups within insignificant difference and by the way could validate our result by studying just the outcome measures between the both groups.

By logic, based on the GA at delivery, our study revealed that there was a significant difference between the both studied groups regarding the birth weight $(2.87 \pm 0.378$ and $3 \pm 0.24 \mathrm{Kg}$ ) for the oral and vaginal group respectively and it is considered significant difference ( $p$ value $=0.022$ ). Of note most of our population delivered average-weight newborns $(83.3 \%$ and $100 \%)$ for the oral and vaginal group respectively ( $p$ value $<0.001$ ) it could be explained as the longer the GA the more the increase in the fetal growth and by the way birth weight taking into consideration the normal intrauterine environment. We never forget that the maternal weight and weight gain during pregnancy have a dramatic effect on such outcome variable and both were of insignificant difference between both groups.

Such data were supported by multiple previous studies including Dodd JM et al, 2013, reviewed thirty- 
six randomized controlled trials (8523 women and 12,515 infants) were included, progesterone versus placebo for patients high risk for PTL, progesterone was associated with a statistically significant reduction in the risk of perinatal mortality, reduction in the risk of infant birth weight less than $2500 \mathrm{~g}$ (one study; 70 infants; RR 0.52, $95 \%$ CI 0.28 to 0.98$)^{[25]}$.

With regard to infant's birth weight, Azin Alavi, 2016, revealed that with vaginal progesterone treatment there was significantly a higher birth weight than others ${ }^{[26]}$. Similarly, Hassan et al. observed a 53\% reduction in low birth weight as a result of vaginal progesterone suppository treatment, which is consistent with the finding of the present research $^{[27]}$.

Depending on the length of gestation and birth weight the Apgar score at one and five minutes after delivery would be affected, our study showed a significant difference in the Apgar score at one minutes post delivery, it was more than 7 in most of our population $(73.6 \%$ and $90.9 \%$ ) in the oral and vaginal group respectively and it is considered significant difference between both groups ( $p$ value $=0.007$ ). Not only the GA and birth weight, but also to the intrauterine life and its quality have a direct impact. Apgar score at one minute post delivery mainly indicated to the need for neonatal resuscitation and the presence of infection or placental insufficiency have a direct and independent relation to such outcome away from the birth weight. We could fix such contributing variables and their effect on our study as all the distribution of the demographic variables among the patients in the both studied groups were statistically insignificant ( $p$ value $>0.05$ ).

In 2006, a meta-analysis by Aravinthan Coomarasamy et al, evaluated the use of progesterone in prevention of preterm delivery in high risk patients. A total of nine randomized control trials were evaluated comprising of about 500 patients. It showed decline in PTL as well as in RDS with progesterone treatment ${ }^{[28]}$. A similar study was carried out by Sedigheh BORNA and Noshin SAHABI in Tehran in 2004, compared the use of progesterone versus no treatment in patients with threatened PTL, they noticed a significant raise in mean latency until delivery, decrease in RDS, and decrease in low birth weight in progesterone $\operatorname{arm}_{\text {group }}{ }^{[2]}$.

Strangely there was insignificant difference between the both studied groups regarding the Apgar score at five minutes post delivery, it was more than 7 in most of our population ( $81.9 \%$ and $90.9 \%$ ) in the oral and vaginal group respectively and it is considered insignificant difference between both groups ( $p$ value $=0.1$ ). We could be explained by; first, most of our population delivered between $34^{0 / 7}$ and $36^{6 / 7}$ weeks' gestation, mild preterm $(61.1 \%$ and $71.2 \%)$ and a considered percentage delivered after the completed 37 weeks' gestation, full term, $(26.4 \%$ and $28.8 \%)$ for the oral and vaginal group respectively. Second, most of our population delivered average-weight newborns $(83.3 \%$ and $100 \%$ ) for the oral and vaginal group respectively. Third, insignificant difference regarding the distribution of the risk factors, including the antenatal infection $(\mathrm{BV}$, PPROM or UTI), between the two studied groups ( $p$ value $=0.587$ ). Fourth, the effectiveness of the management given, including the accurate and early diagnosis of any abdominal pains plus the suitable indicated treatment including the screened antibiotic according o culture and sensitivity and betamethasone to enhance lung maturation and its extra pulmonary effect, never to forget the good post delivery early neonatal care.

Our clinical trial showed that only 21 early neonates (15.2\%) of our population needed NICU admission, 15 cases from oral group $(20.8 \%)$ and 6 cases from vaginal group $(9.1 \%)$. Only 3 cases died, all were within the oral group.

Strangely Sedigheh BORNA and Noshin found no significant difference in the recurrent PTL, admission to NICU and neonatal sepsis for the progesterone and control groups, respectively ${ }^{[29]}$.

Another multicenter randomized trial was performed to assess whether a cervical pessary could effectively prevent poor pregnancy outcomes, subjects were randomized to cervical pessary placed between 16 and 20 weeks' gestation or no pessary. In unselected women with multiple pregnancies, prophylactic use of the cervical pessary did not reduce poor perinatal outcome ${ }^{[30]}$.

\section{LIMITATIONS OF THE STUDY}

Our study has a few limitations. One is the small sample size of our study. Among the limitations of this research is that it was conducted only in one hospital. The quality of services varies across hospitals.

\section{CONFLICTS OF INTEREST}

There is no conflict of interest.

\section{CONCLUSION}

Both the oral and vaginal routes of progesterone supplementation are of significant value to improve the perinatal outcome in women at high risk for PTL, in addition our research suggests that the vaginal route is of better and significant results.

It suggests a measurement of the serum level of progesterone in blood across groups and comparing the effect of vaginal versus oral progesterone as a prophylactic treatment on women at high risk for PTL. 


\section{CONCLUSION}

1. National Center for Health Statics (NVSR). Deaths and percentage of total deaths for the 10 leading causes of neonatal and postnatal deaths: United States; 2001 [accessed 07.02.05].

2. Goldenberg RL, Culhane JF, Iams JD, Romero R. Epidemiology and causes of preterm birth. Lancet 2008; 371: 75-84.

3. Moster D, Lie RT, Markestad T. Long-term medical and social consequences of preterm birth. $\mathrm{N}$ Engl $\mathrm{J}$ Med 2008; 359: 262-73.

4. O'Brien JM, Adair CD, Lewis DF, Hall DR, Defranco $\mathrm{EA}$, Fusey $\mathrm{S}$, et al. progesterone vaginal gel for the reduction of recurrent preterm birth: primary results from a randomized, double-blind, placebo-controlled trial. Ultrasound Obstet Gynecol 2007; 30: 687-96.

5. European community collaborative study of outcome of pregnancy between 22 and 28 weeks gestation. Working group on the very low birthweight infant. Lancet. 1990; 336: 782-784.

6. Chan K, Ohlsson A, Synnes A, Lee DSC, Chien L, Lee SK et al. Survival, morbidity, and resource use of infants of 25 weeks gestational age or less. Am J Obstet Gynecol. 2001; 185: 220-2.

7. Kramer MS, Demissie K, Yang H, Platt RW, Sauvé $\mathrm{R}$, Liston RJAMA. The contribution of mild and moderate preterm birth to infant mortality. Fetal and Infant Health Study Group of the Canadian Perinatal Surveillance System. 2000; 284(7): 843-9.

8. Lefebvre F, Glorieux J, St-Laurent-Gagnon T. Neonatal survival and disability rate at age 18 months for infants born between 23 and 28 weeks of gestation. Am J Obstet Gynecol. 1996; 174(3): 833-8.

9. Elder DE, Hagan R, Evans SF, Benninger HR, French NPJ. Hospital admissions in the first year of life in very preterm infants. Paediatr Child Health. 1999; 35(2): $145-50$

10. Hamilton BE, Minino AM, Martin JA, Kochanek KD, Strobino DM, Guyer B. Annual summary of vital statistics: 2005. Pediatrics 2007; 119: 345-60.

11. Steer P. The epidemiology of preterm labor. BJOG $2005 ; 112: 1-3$

12. Ibrahim M, Ramy A, Younis A. Progesterone supplementation for prevention of preterm labor: a randomized controlled trial. Middle East Fertil Soc J 2010; 15: 39-41.
13. Check JH, Lee G, Epstein R, Vetter B. Increased rate of preterm deliveries in untreated women with luteal phase deficiencies. Gynecol Obstet Invest 1992; 33: 183-4.

14. Fuchs F, Stakeman G. Treatment of threatened premature labor with large doses of progesterone. Am J Obstet Gynecol 1960; 79: 172.

15. Fuchs AR, Fuchs F. Endocrinology of human parturition: a review. Br J Obstet Gynaecol 1984; 91: 948-67.

16. Amon E. Preterm labor. In: Reece EA, Hobbins JC, editors. Medicine of the fetus and mothers. Philadelphia: Lippincott-Raven; 1999. p. 1529-79.

17. Berghella V, Blackwell S, Anderson B, Chauhan SP, Copel J, et al. (2012) Progesterone and preterm birth prevention. Am J Obstet Gynecol 206(5): 376-386.

18. O'Brien JM, Adair CD, Lewis DF, Hall DR, Defranco EA, Fusey S, et al. Progesterone vaginal gel for the reduction of recurrent preterm birth: primary results from a randomized, double-blind, placebo-controlled trial. Ultrasound in obstetrics \& gynecology: the official journal of the International Society of Ultrasound in Obstetrics and Gynecology. 2007 Oct; 30(5): 687-96.

19. Neeta Natu, Shikha Sonker, Nootan Chandwaskar, Sweta Agrawal. Role of oral micronized progesterone versus vaginal progesterone for prevention of preterm labour. International Journal of Reproduction, Contraception, Obstetrics and Gynecology Natu N et al. Int J Reprod Contracept Obstet Gynecol. 2017 May; 6(5): 1797-1799.

20. Su LL, Samuel M, Chong YS. Progestational agents for treating threatened or established preterm labor Cochrane Database Syst Rev. 2014 ; ( 1): CD006770.

21. Society for Maternal-Fetal Medicine Publications Committee. Progesterone and preterm birth prevention: translating clinical trials data into clinical practice. American journal of obstetrics and gynecology. 2012; 206(5): 376-86.

22. Azza A. Abd El Hameed. Vaginal versus intramuscular progesterone in the prevention of preterm labor and their effect on uterine and fetal blood flow Middle East Fertility Society Journal. 2012; 17: 163-169.

23. Da Fonseca EB, Bittar RE, Carvalho MH, Zugaib M. Prophylactic administration of progesterone by vaginal suppository to reduce the incidence of spontaneous preterm birth in women at increased risk: 
a randomized placebo-controlled double-blind study. AJOG; 2003, 188 (2): 419-24.

24. Wilasinee Areeruk \& Vorapong Phupong. A randomized, double blinded, placebo controlled trial of oral dydrogesterone supplementation in the management of preterm labor. Scientific Reports | 6:20638 | DOI: 10.1038/srep20638

25. Dodd JM, Jones L, Flenady V, Cincotta R, Crowther CA. Prenatal administration of progesterone for preventing preterm birth in women considered to be at risk of preterm birth. Cochrane Database Syst Rev. $2013 ;(7): C D 004947$

26. Azin Alavi, Hosein Hamadiyan and Masoomeh Darijani. Effect of vaginal progesterone suppository (200 $\mathrm{mg}$ ) on preventing preterm labor after the inhibition of uterine contractions: A randomized clinical trial .International Journal of Medical Research \& Health Sciences, 2016, 5, 10:21-26
27. Hassan SS, Romero R, Vidyadhari D, Fusey S, Baxter $\mathrm{JK}$, Khandelwal M, et al. Vaginal progesterone reduces the rate of preterm birth in women with a sonographic short cervix: a multicenter, randomized, double-blind, placebo-controlled trial. Ultrasound in Obstetrics \& Gynecology. 2011; 38(1):18-31.

28. Coomarasamy A, Thangaratinam S, Gee H, Khan KS (2006) Progesterone for the prevention of preterm birth: A critical evaluation of evidence. Eur J Obstet Gynecol Reprod Biol 129: 111-118.

29. Borna S, Sahabi N (2008) Progesterone for maintenance tocolytic therapy after threatened preterm labour: A randomised controlled trial. Aust N Z J Obstet Gynaecol 48: 58-63.

30. Liem S, Schuit E, Hegeman M, Bais J, de Boer K, et al. (2013) Pessaries for prevention of preterm birth in women with a multiple pregnancy (ProTWIN): a multicentre, open-label randomised controlled trial. Lancet 382(9901): 1341-1349. 